\title{
EDIFICIO DE OFICINAS EN EL PASEO DE RECOLETOS. MADRID/ESPAÑA.
}

\author{
(OFFICE BUILDING ON THE PASEO DE RECOLETOS, MADRID/SPAIN)
}

R. Andrada Pfeiffer y R. Andrada G. Parrado, Arquitectos.

$131-149$

P. Criado Juárez, Aparejador.

\section{RESUMEN}

El proyecto intentó dar respuesta a los problemas que plantea la construcción de un edificio moderno de oficinas en un entorno urbano muy significativo, caracteristico y consolidado de Madrid.

Se han valorado tanto los problemas de enlace con los edificios medianeros, como los problemas de situación (esquina de una manzana consolidada en el paseo o eje Castellana-Recoletos), los problemas de lenguaje arquitectónico (composición de las fachadas) y los de su construcción y sus materiales (piedra y cristal).

Por tanto, se concibe el edificio a partir del programa de necesidades (oficinas en "planta paisaje"), como expresión de su situación urbana, en un entorno cuya singularidad e importancia, han ido sugiriendo las formas, los materiales y su expresión.

\section{SUMMARY}

The projected building is an attempt to respond to the problems resulting from the construction of a modern office building in a significant, characteristic and consolidated urban environment of Madrid.

Among the problems considered by the authors are their relationship with the existing medium-sized buildings, as well as location (the corner of a consolidated block on the avenue-axis Castellana-Recoletos), arquitectonic language (composition of façades), and construction and construction materials (stone and glass).

Therefore, the building is conceived from a plan of necessities (offices set in "landscape floors"), and as an expression of its urban location, in an area whose uniqueness and importance themselves have suggested the shapes, the materials and their expression.
En un solar con emplazamiento muy significativo en Madrid (Paseo de Recoletos con vuela a Olózaga), y que forma una esquina urbanísticamente realzada por el retranqueo del Palacio del Marqués de Salamanca, proyectamos un edificio, sede de las aseguradoras Grupo Victoire, con la pretensión de dar respuesta a los problemas que en tan importante entorno y en una manzana muy consolidada plantea la construcción de un moderno edificio de oficinas (dispuesto en "planta paisaje"). (Fig. 1.)

El planeamiento vigente (Plan Especial Villa de Madrid) nos exigía completar la manzana, ocultando medianerias, e igualando alturas. Se han compuesto los volúmenes y las fachadas con un lenguaje que estableciera diálogo con ese ya señalado importante entorno, significando la esquina en chaflán con una planta de torreones y un remate, equilibrando así los frentes de la manzana. (Fig. 2.)

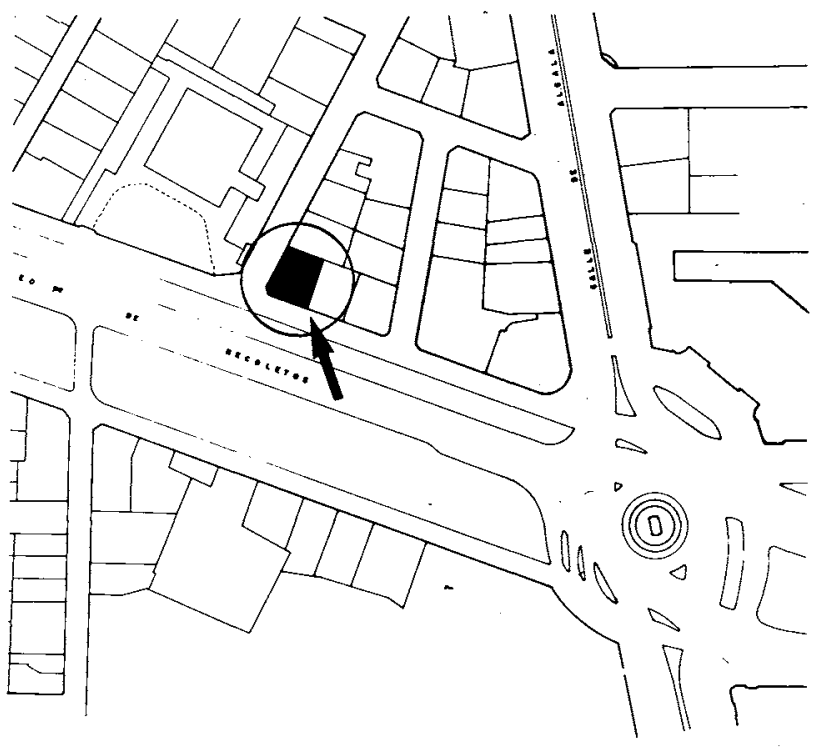

Fig. 1.-Emplazamiento del edificio en la trama urbana. 

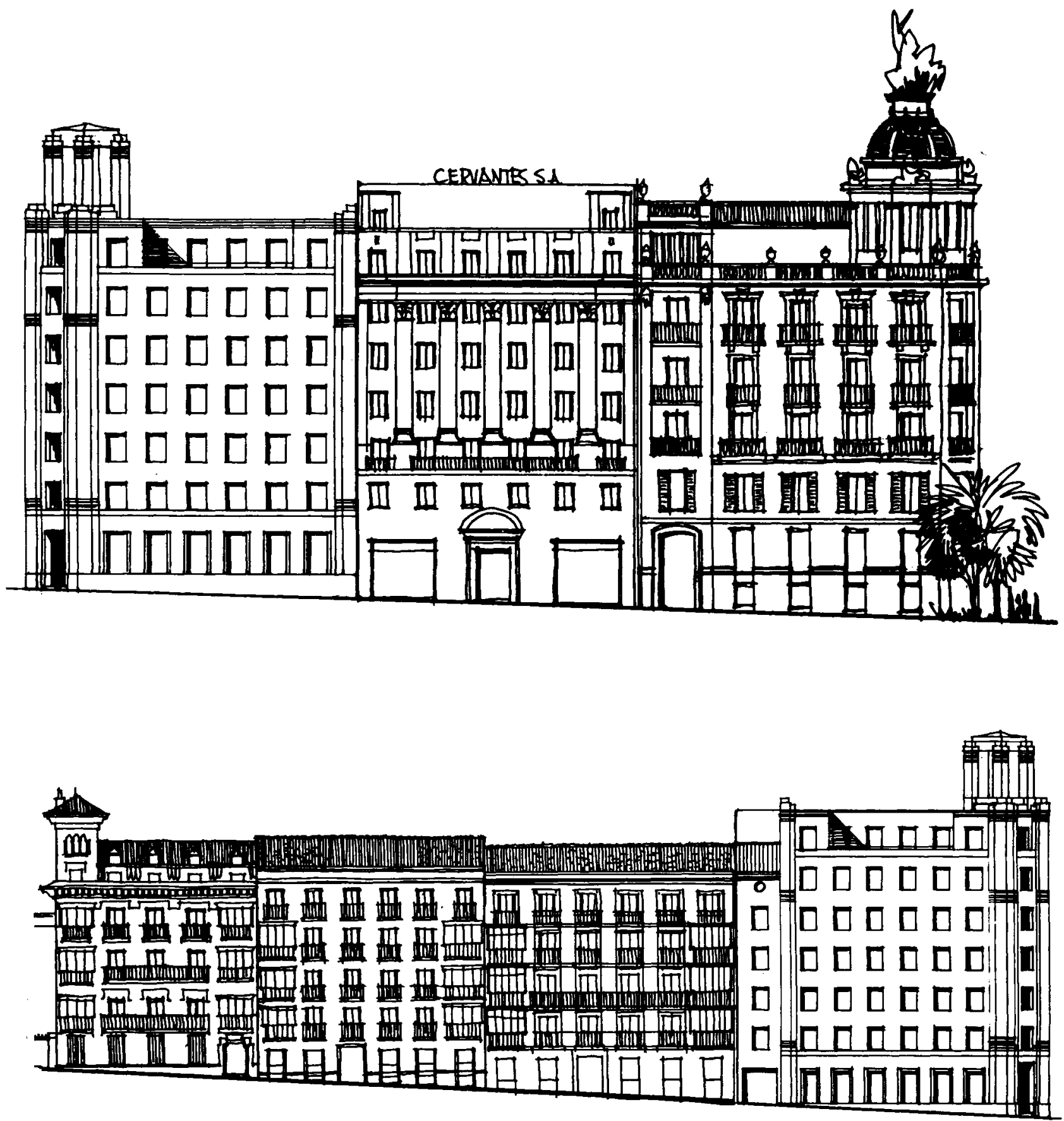

Fig. 2.-El edificio en la manzana.

El problema de enlace, resuelto de manera directa en Recoletos, se resuelve sin esfuerzo visual en la calle Olózaga al repetir simétricamente la fachada de Recoletos (simetría remarcada por las pilastras y el zócalo) lo que permite crear un cuerpo intermedio de unión. Se consigue además con esta simetria equilibrar la imagen propia del edificio. (Figs. 3 y 4.)

Las fachadas se intentan valorar tanto por su compo-

(c) Consejo Superior de Investigaciones Científicas

Licencia Creative Commons 3.0 España (by-nc) sición (orden y proporción de sus huecos en ritmo vertical) como por su construcción (piedra y cristal), buscando un punto de equilibrio entre la exigencia exterior (entorno y manzana) y la necesidad funcional interior (diafanidad de la planta paisaje). La disposición en planta de la estructura y del núcleo vertical está condicionada por la rampa del garaje que se desarrolla perimetralmente en el solar, e intenta además absorber su irregularidad. 


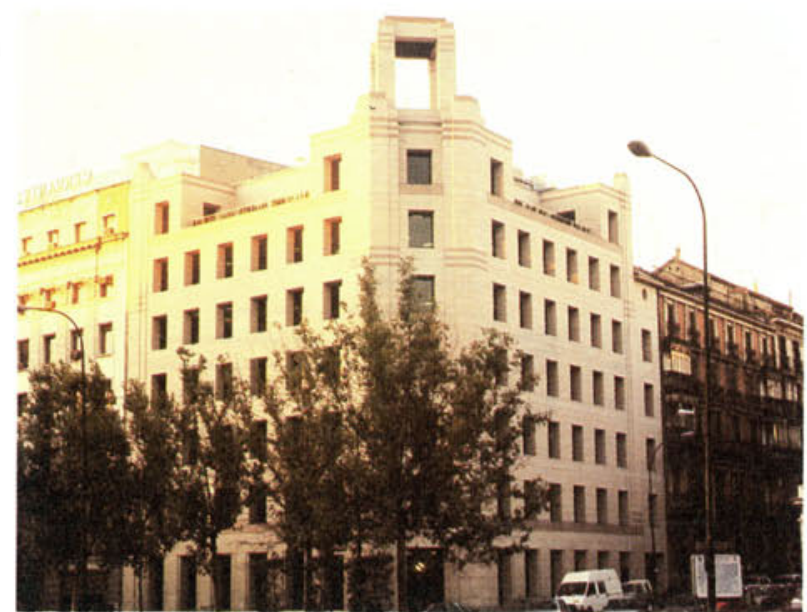

Fig. 3.-Vista general.

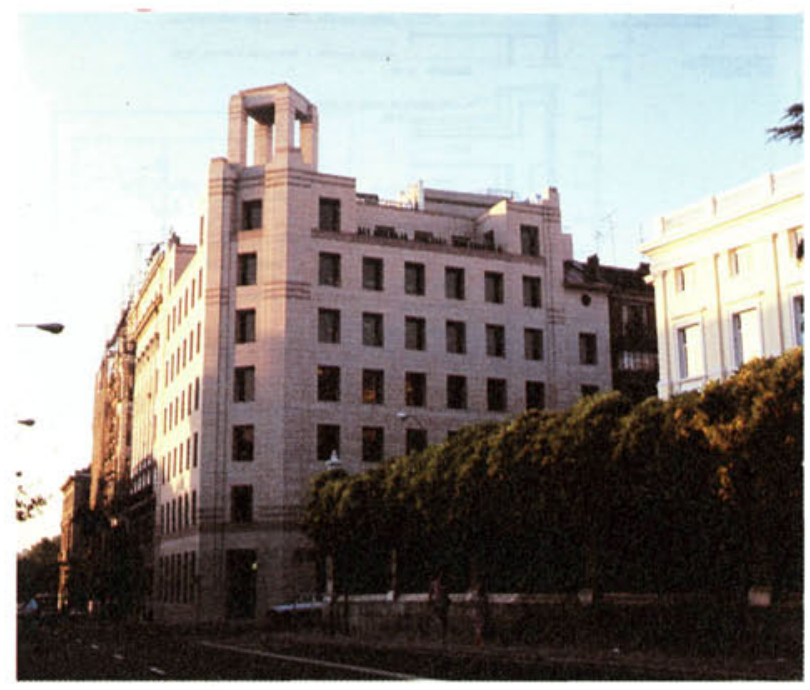

Fig. 4.-Vista general.

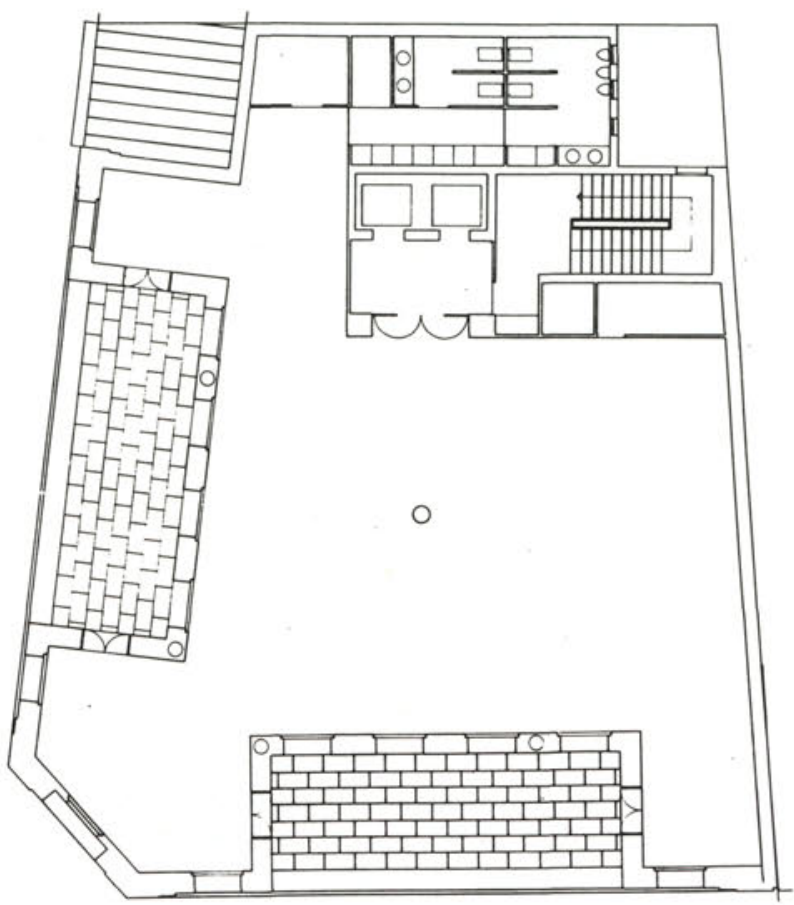

La planta baja de atención al público con acceso por el chaflán y espacialmente simétrica es, por deseo de la propiedad, independiente del resto del edificio, que tiene entrada distinta desde Olózaga, donde también comienza la rampa de garaje.

Es quizá en esta.planta baja donde mejor se reflejan tanto la pequeña complejidad de uso, accesos, estructuras, ordenanzas... como la irregularidad del solar. (Fig. 5.)

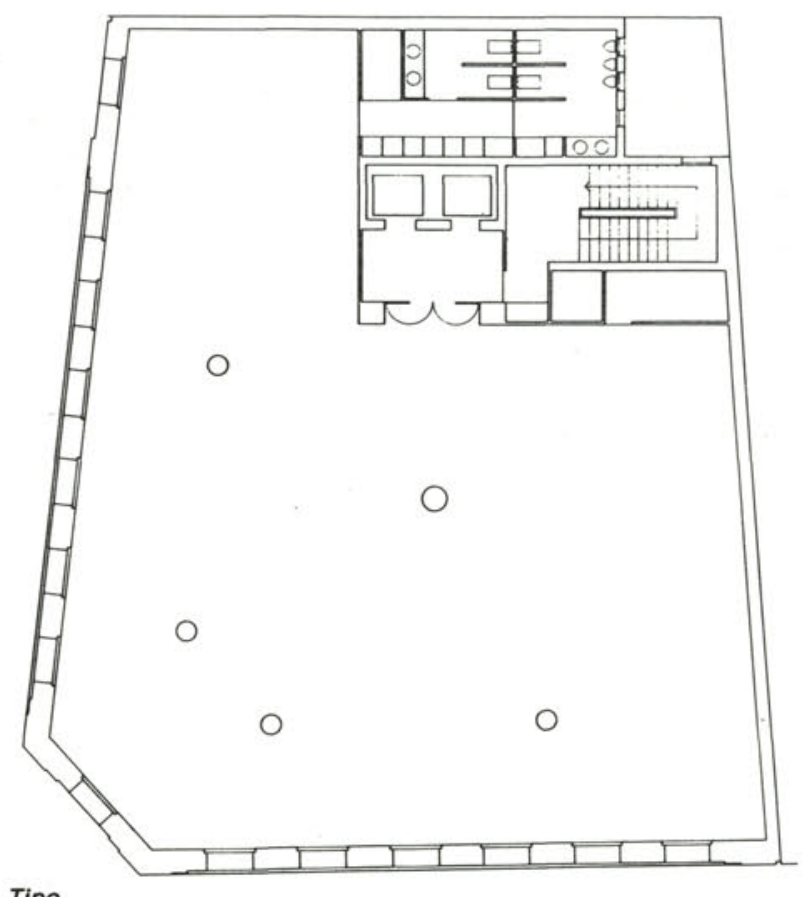

Tipo

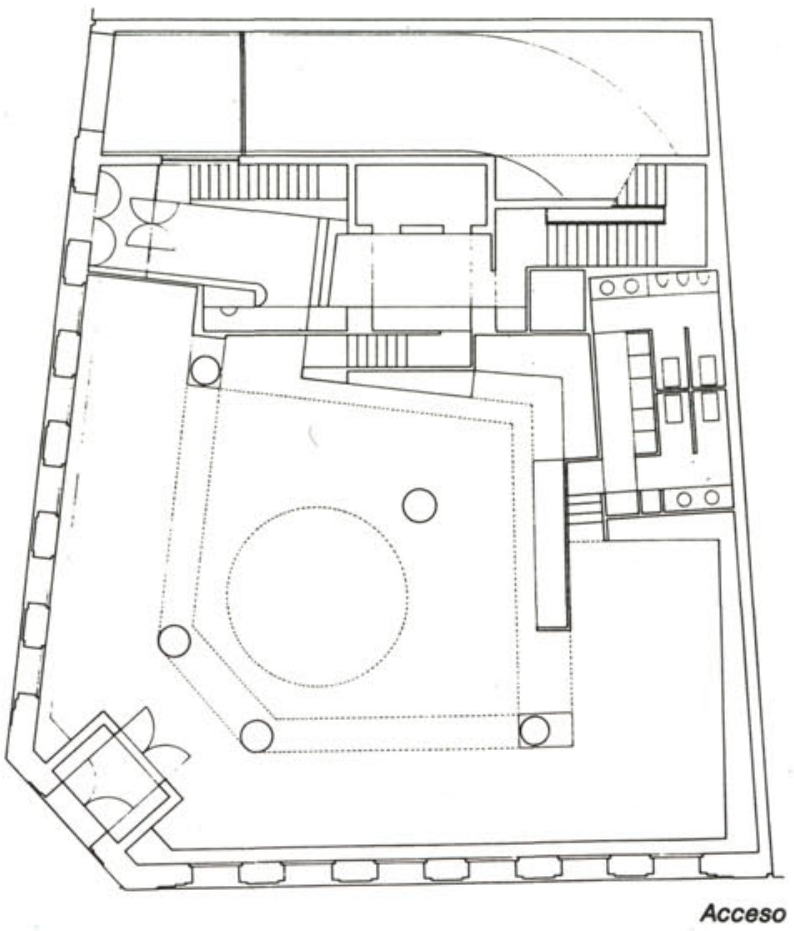




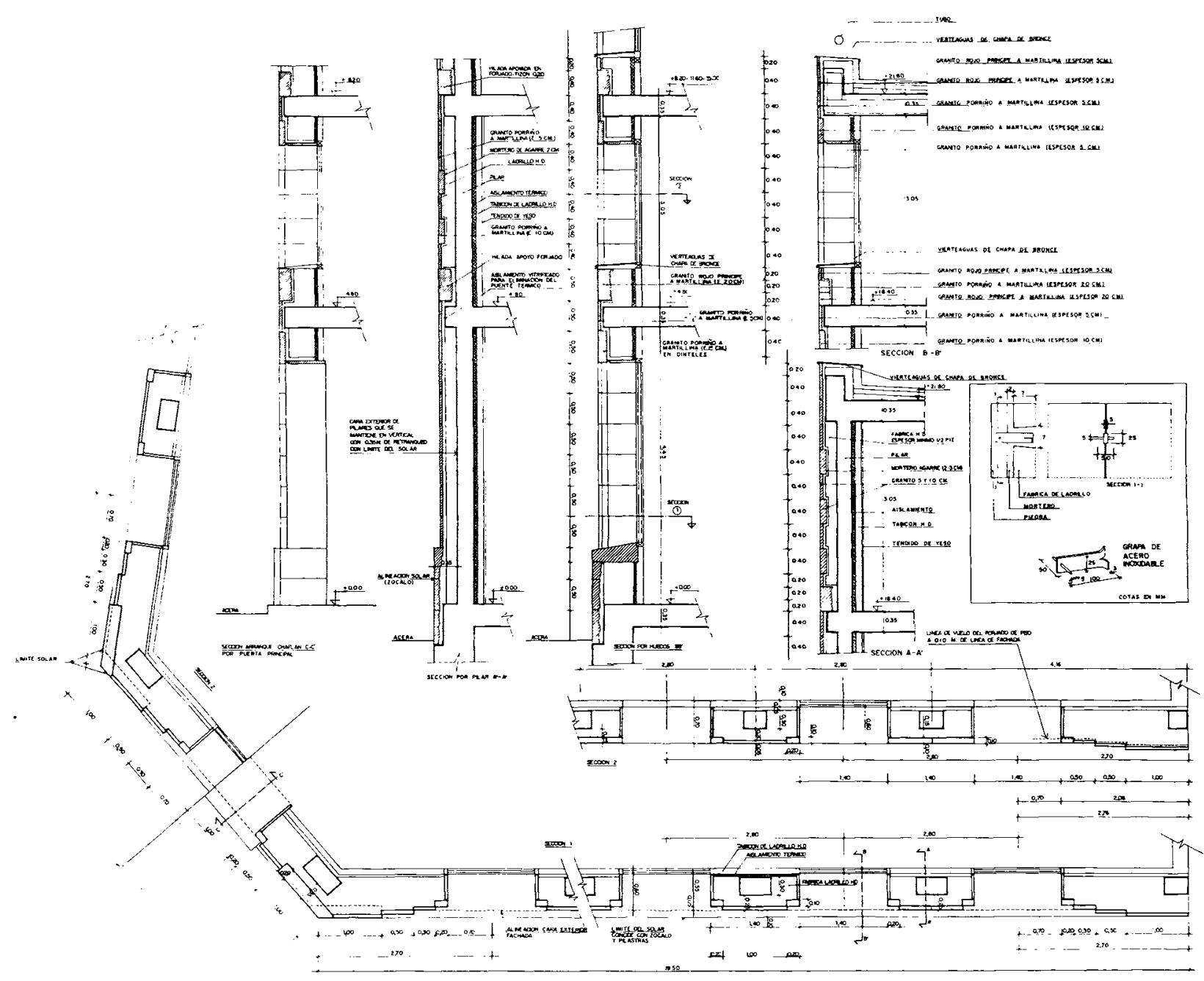

Fig. 6.-Organización constructiva de las fachadas.

\section{Organización constructiva de la fachada (Fig. 6)}

Chapado grueso de piedra de granito $(5.10 \mathrm{~cm}$ de espesor), descansando sobre cada forjado de piso, mediante hilada de $20 \mathrm{~cm}$ de espesor; trasdosado interior de fábrica de ladrillo doble hueco, y engrapado con ganchos de acero inoxidable (cuatro por piedra). Al interior, cámara de aire con aislamiento térmico, tabicón de ladrillo hueco doble con yeso, y revestimiento interior de paneles de madera sobre rastrel.

La carpintería exterior es doble, de aluminio anodizado en color bronce, y con doble cristal de $10 \mathrm{~mm}$ de espesor. Aspectos constructivos interesantes y que influyen decisivamente en el resultado estético del edificio son el grosor y despiece de la piedra, y la doble carpinteria de aluminio oculta. 
1. Grosor de la piedra (Figs. 7, 8,9 y 10 )

La utilización del granito, rosa porriño en fachadas y rojo sueco en bandas horizontales, alternando es- pesores, nos permite conseguir en esquinas y mochetas grosor aparente de $10 \mathrm{~cm}$, y aligerar el peso donde no sea visible; se consigue, además, eliminar la sensación de simple aplacado.

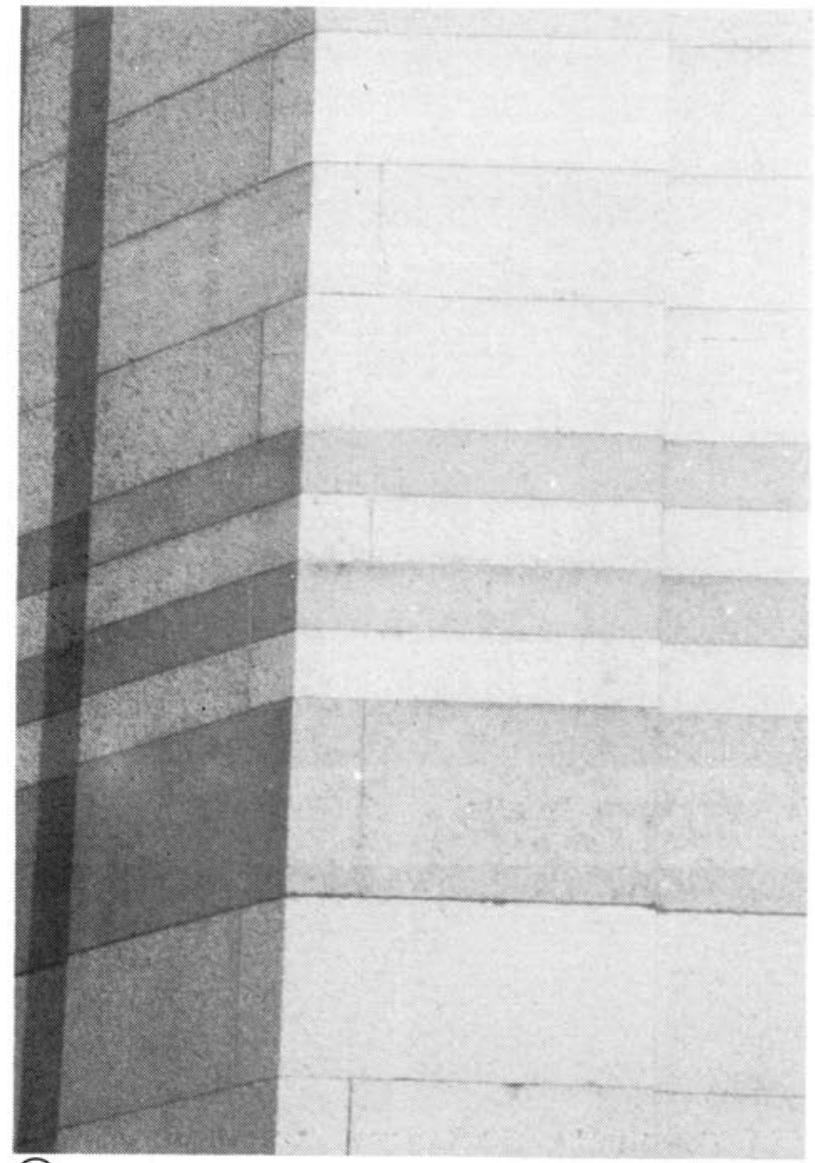

(7)

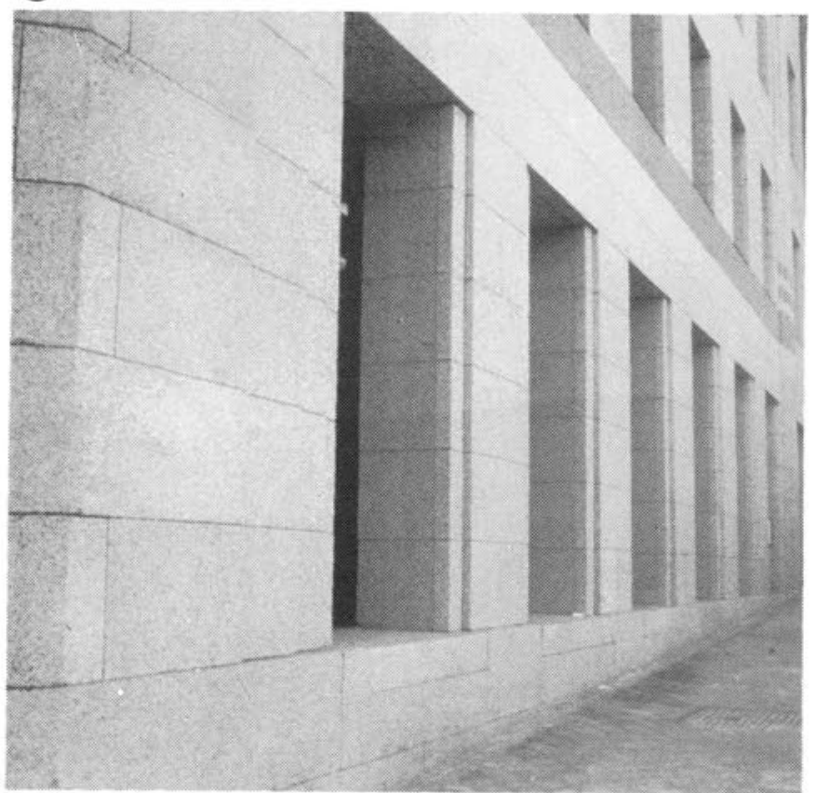

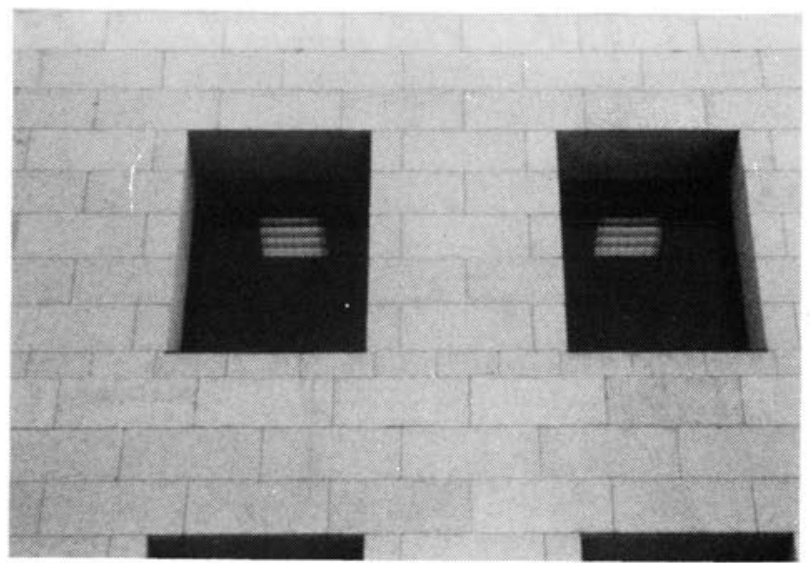

(9)

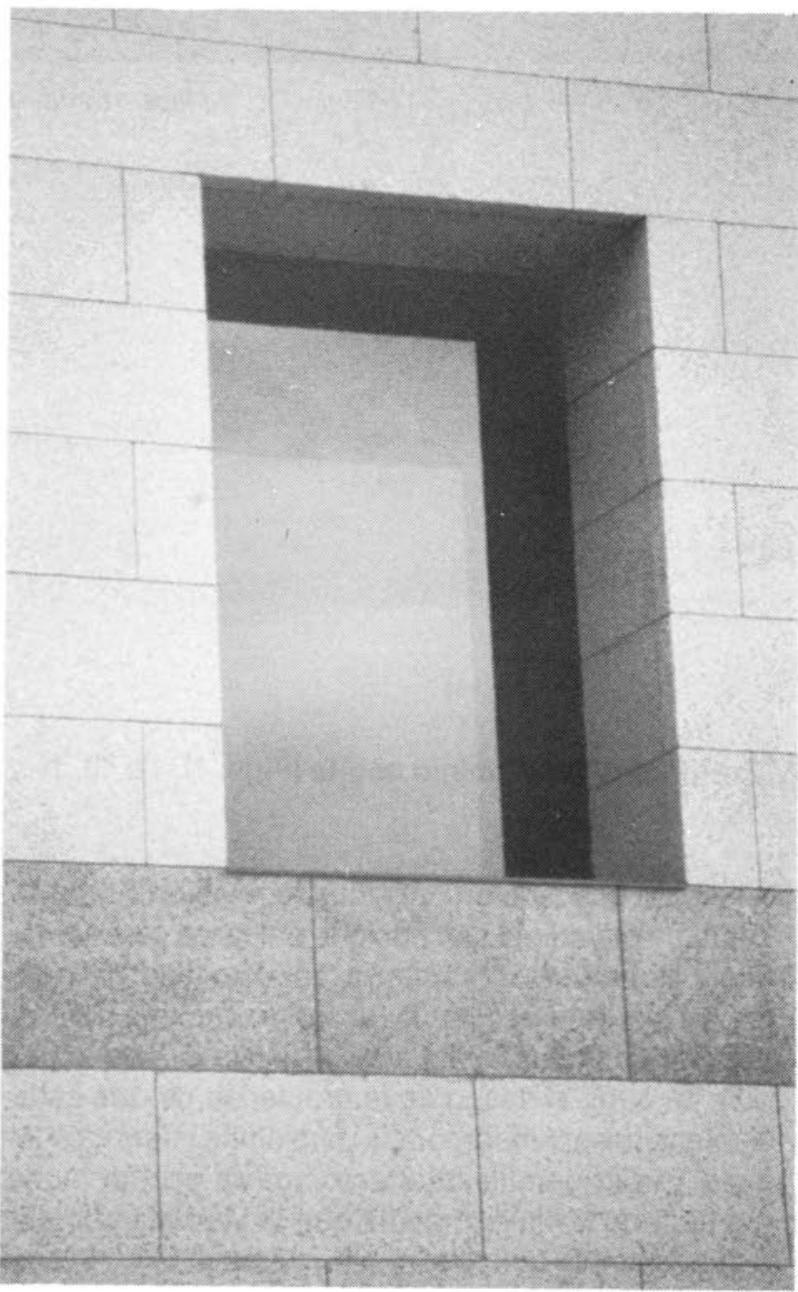

(10)

Figs. 7, 8, 9 y 10.-Detalles de fachada. 

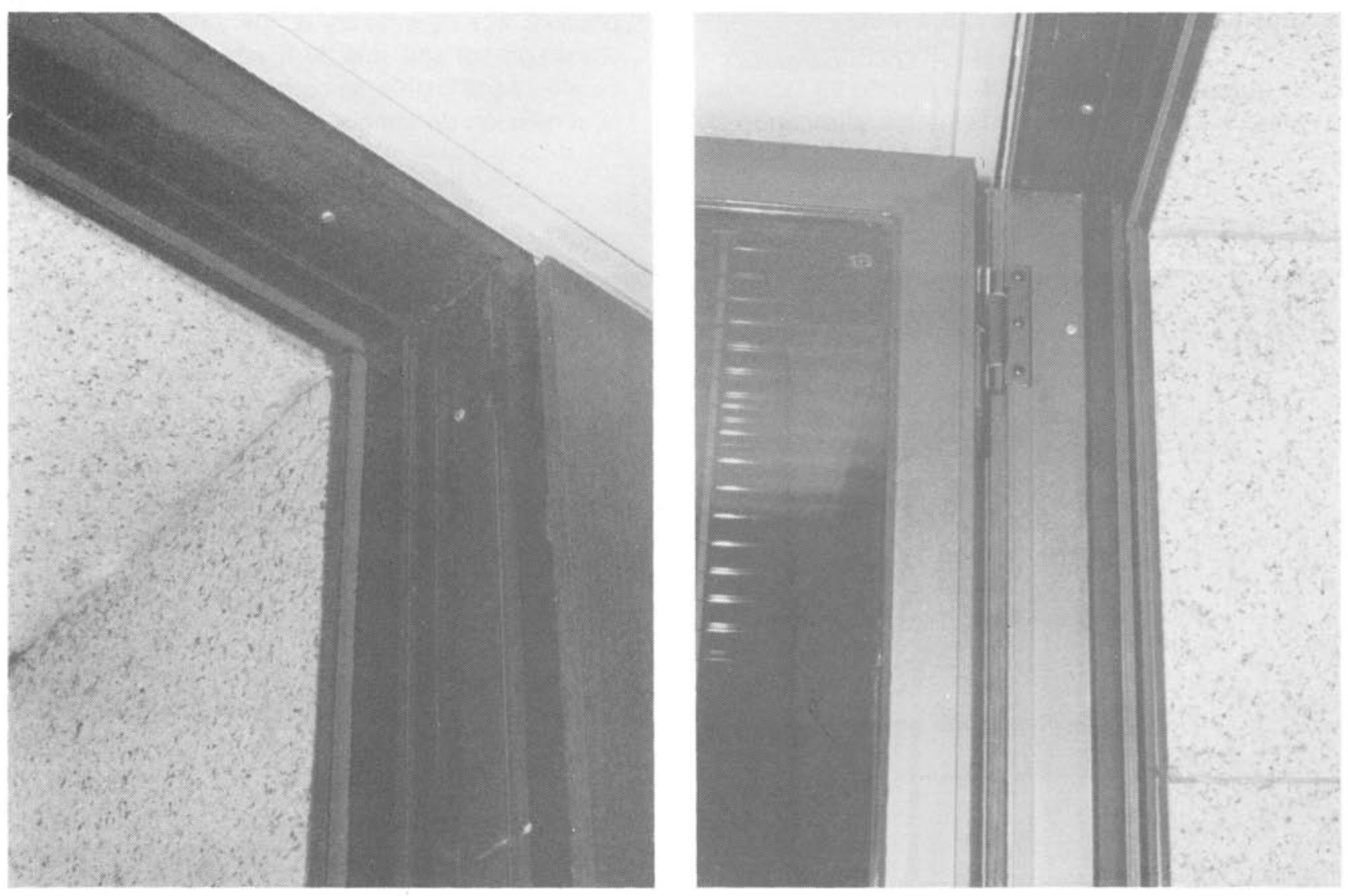

Figs. 11 y 12.-Detalle ventana abierta.

2. Carpintería de aluminio oculta (Figs. 11, 12, 13, 14 y 15)

El efecto buscado en proyecto de relación visual directa piedra-cristal se consigue únicamente ocultando la carpintería; carpintería, por otro lado, necesaria, ya que el hueco debía de ser practicable para su limpieza. El tamaño del hueco (1,40 m de ancho por $2 \mathrm{~m}$ de alto), el deseo de la propiedad de que cada ventana tuviera incorporada persianilla interior de lamas, y la exigencia arquitectónica de ocultar dicha carpintería (lo que impedía que la ventana pudiera ser pivotante), obligó al diseño y fabricación de una ventana "especial" para este caso concreto, tras lo cual, salió este tipo de ventana al mercado.

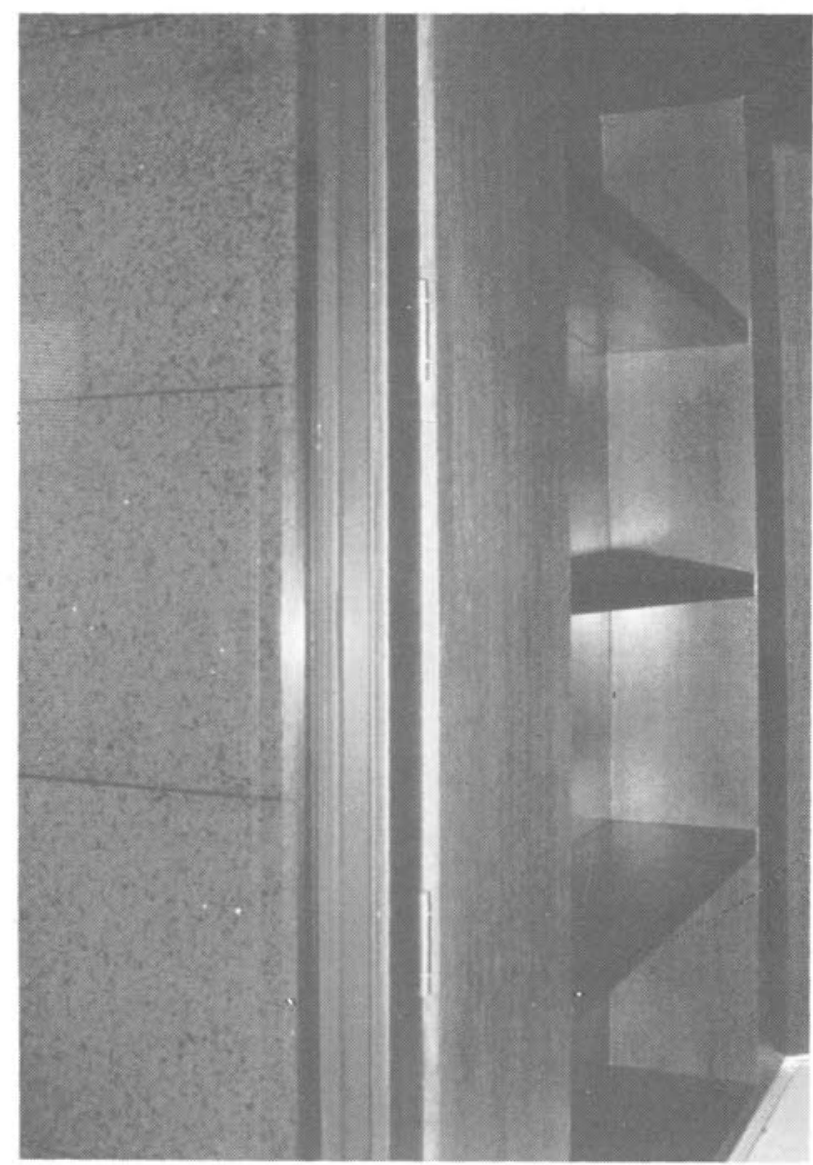

Fig. 13.-Detalle ventana cerrada. 


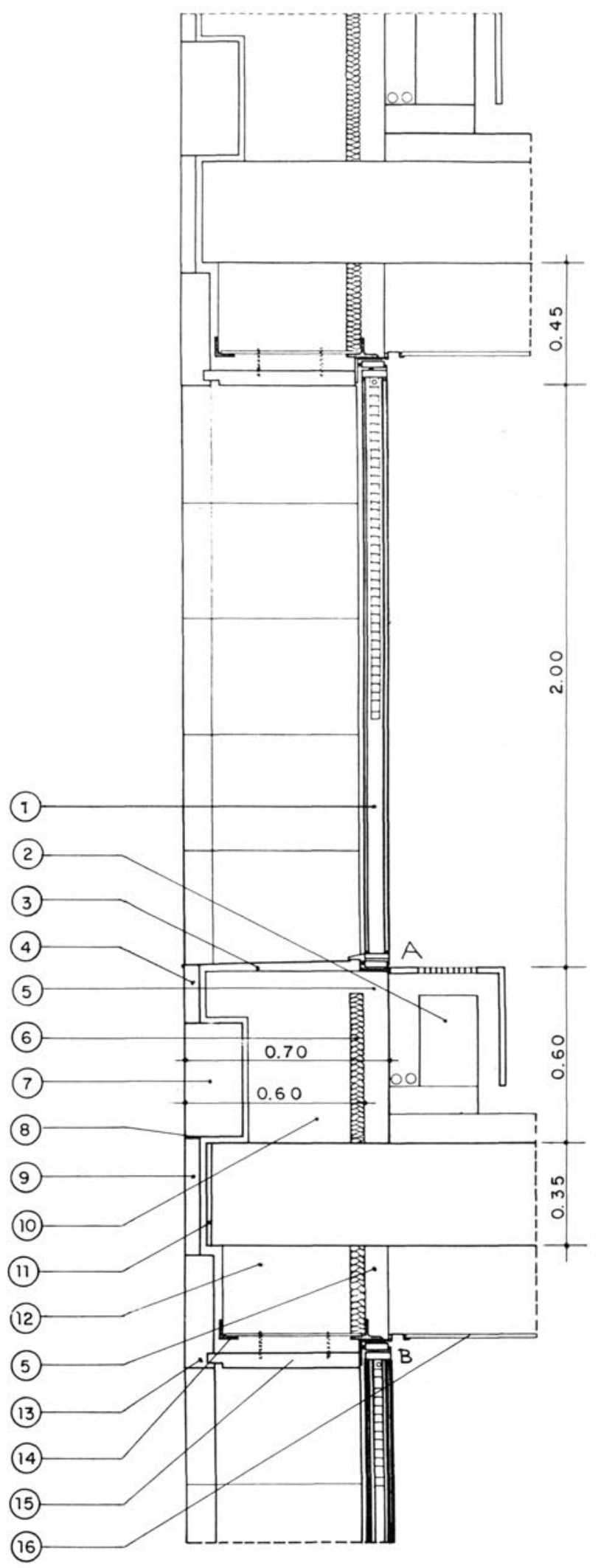

Fig. 14.-Sección vertical por hueco.

1. Carpinteria doble de aluminio bronce.

2. Fancoil - Mueble cubre fancoil de madera.

3. Vierteaguas de chapa de aluminio de $3 \mathrm{~mm}$.

4. Granito $5 \mathrm{~cm}$.

5. Tabique hueco doble.

(c) Consejo Superior de Investigaciones Científicas Licencia Creative Commons 3.0 España (by-nc)
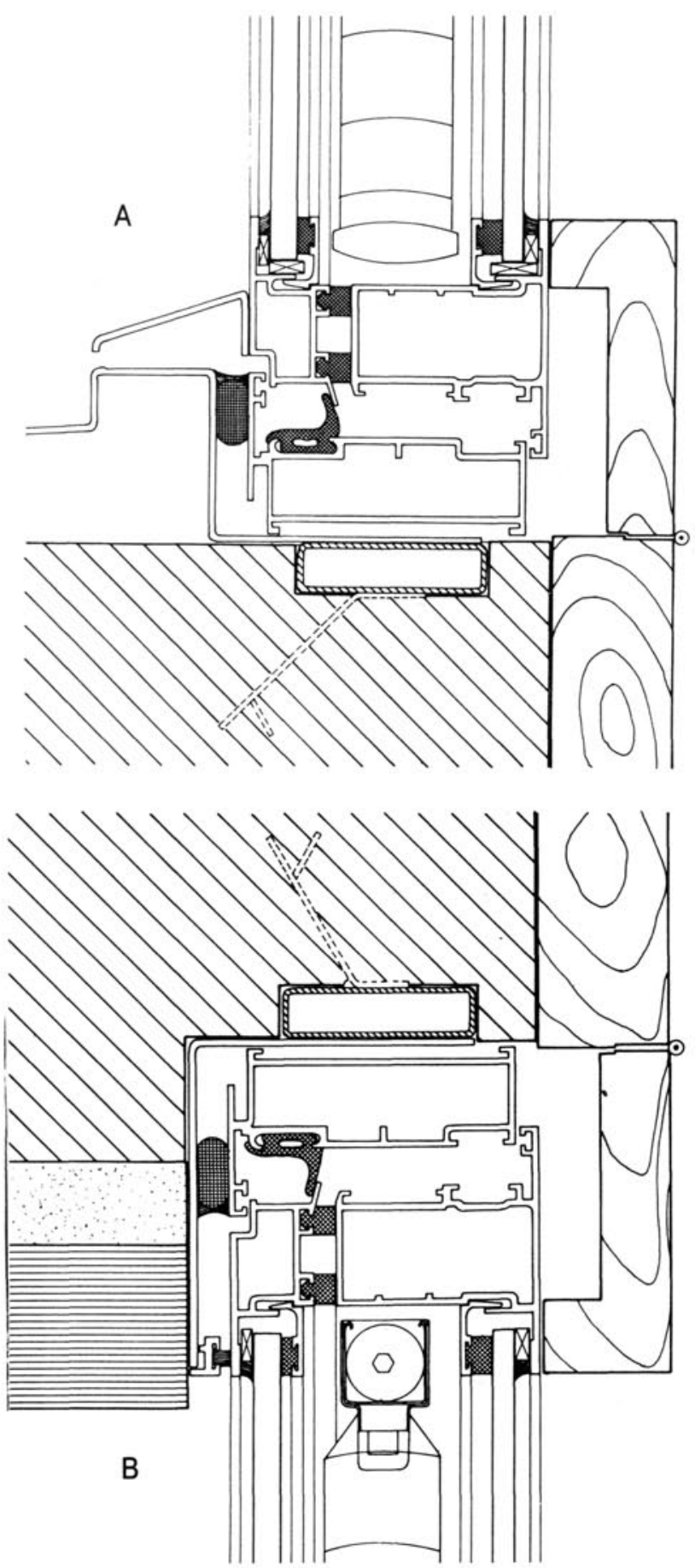

Fig. 15.-Detalles de carpintería. (Ver Fig. 14.)

6. Aislamiento $5 \mathrm{~cm}$.

7. Granito. Hilada de apoyo $20 \mathrm{~cm}$.

8. Junta de neopreno.

9. Granito $5 \mathrm{~cm}$.

10. Fábrica de ladrillo.

11. Polydros.

12. Fábrica de Iadrillo.

13. Granito $10 \mathrm{~cm}$.

14. Armadura de cuelgue.

15. Granito de $5 \mathrm{~cm}$.

16. Falso techo.

http://informesdelaconstruccion.revistas.csic.es 
Los interiores, dotados de las instalaciones y servicios del caso, están tratados con gran austeridad cromática, habiéndose cuidado el remate y acabado de los mismos. (Figs. 16, 17, 18, 19, 20 y 21.)

Y para terminar estos breves comentarios cabe decir que el edificio se ha concebido a partir del programa de necesidades, como expresión de su situación urbana en un entorno, cuya singularidad e importancia han ido sugiriendo las formas, los materiales y su expresión.

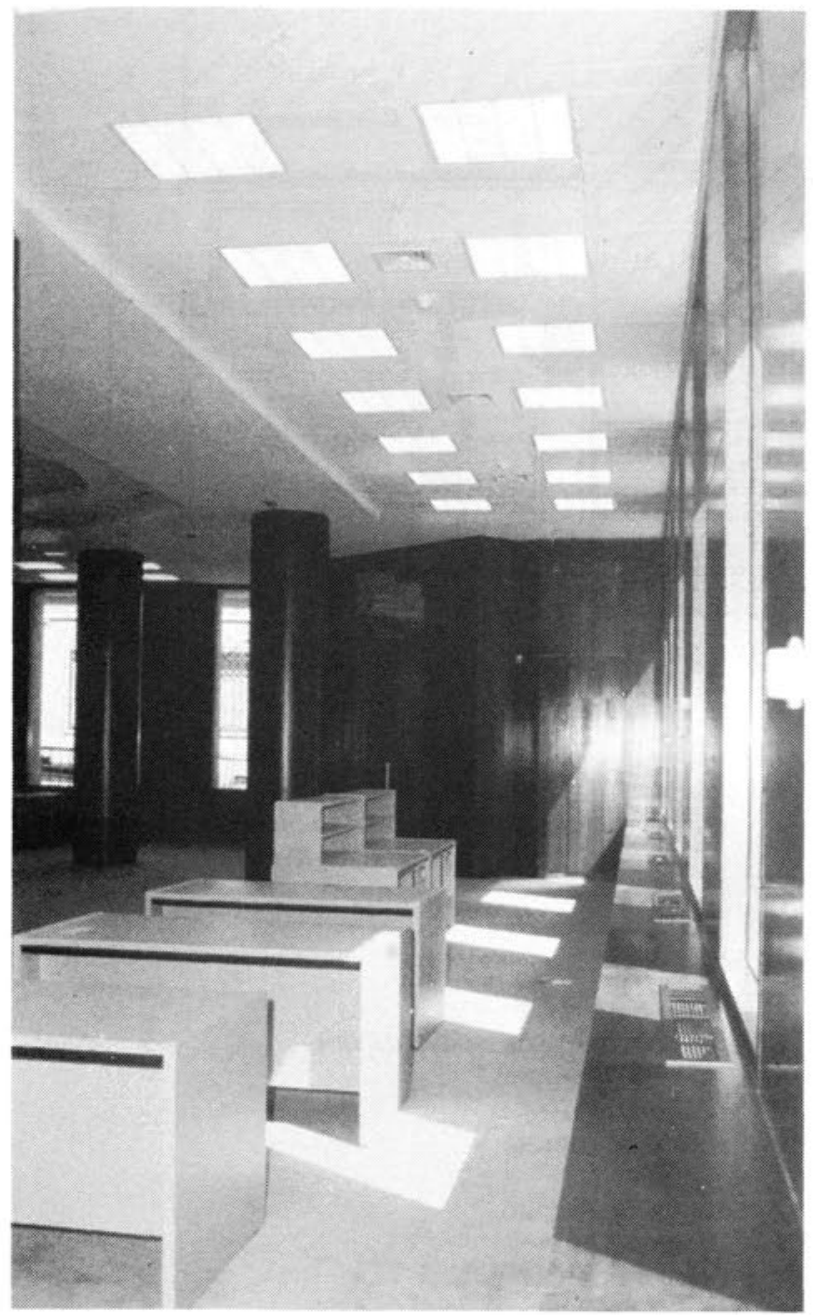

Fig. 16.-Interior planta baja.

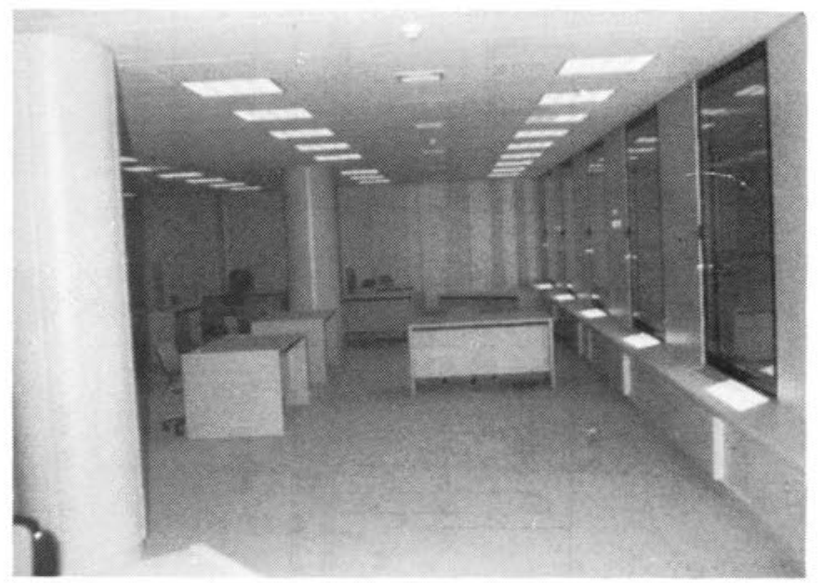

Fig. 17.-Interior planta tipo.

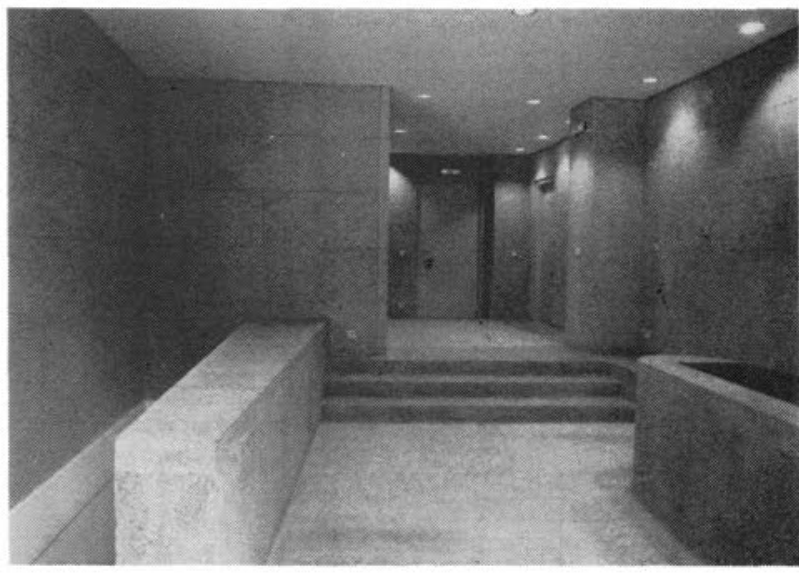

Fig. 18.-Acceso oficinas.

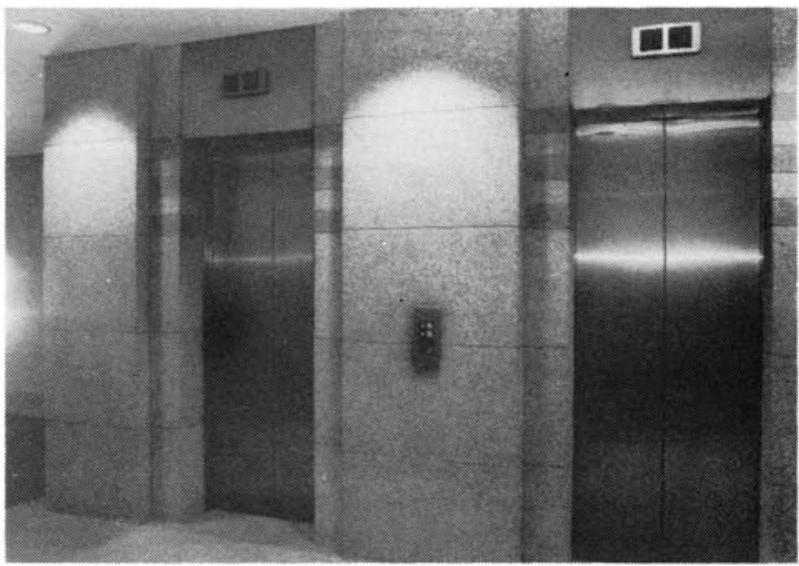

Fig. 19.-Vestibulo de ascensores.

http://informesdelaconstruccion.revistas.csic.es 

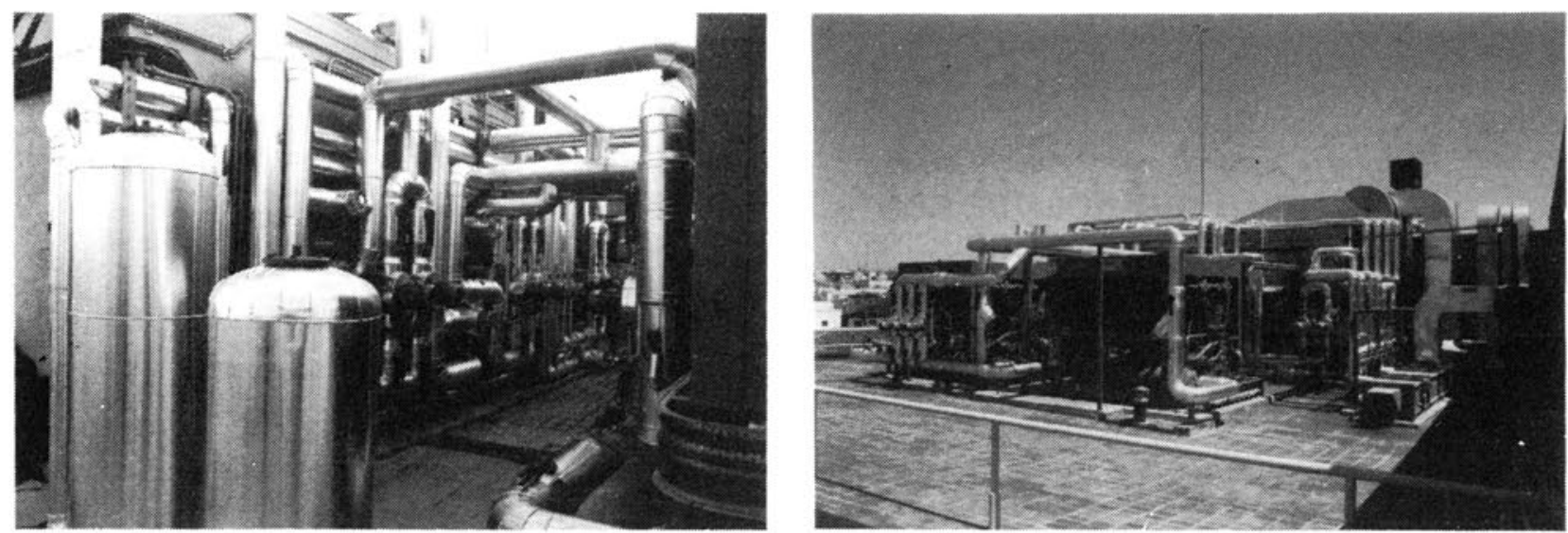

Figs. 20 y 21.-Instalación de climatización en cubierta.

\section{FICHA TECNICA}

Propiedad:

Arquitectos:

Aparejador:

Empresa

Constructora:

Estructura:

Instalaciones:

Control:

Fecha Proyecto:

Fecha Construcción:
GRUPO VICTOIRE - L'ABEILLE, S. A.

RAMON ANDRADA PFEIFFER

RAMON ANDRADA GONZALEZ-PARRADO

PEDRO CRIADO JUAREZ

FERROVIAL, S. A.

OTEP INTERNACIONAL, S. A.

SERELAND, S. A.

SECOTEC, S. A.

1982-83

1984-86

\section{hases para el diseño solar pasivo}

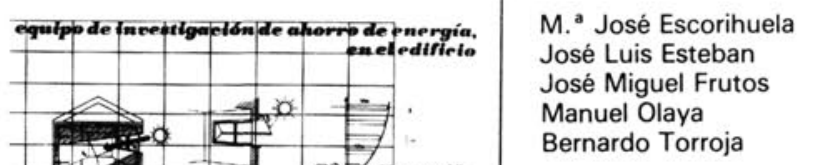
en el edificio

Arturo Garcia Arroyo

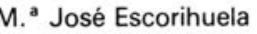

Jose Luis Esteban

Manuel Olaya
Equipo de Ahorro de Energía

Dirección y coordinación: selectividad en la aplicación de los sistemas y procedimientos pasivos dando origen a un ecumenismo arquitectónico solar, al margen de las condiciones climáticas y funcionales específicas de cada caso y lugar.

En este libro, utilizando criterios y metodologia pedagógicos, se dan los fundamentos e instrumentos teórico-prácticos necesarios para el planteamiento de todo proyecto arquitectónico solar pasivo, de acuerdo con los principios éticos y económicos de conservación y ahorro de energia. Es decir: respeto de los presupuestos bioclimáticos, búsqueda de la máxima captación y acumulación de la radiación solar, y esmero en el aislamiento térmico de los cerramientos.

Un volumen encuadernado en cartulina ibiza plastificada, a cinco colores, de $16 \times 23 \mathrm{~cm}$, compuesto de 216 páginas, 217 figuras, 87 gráficos, 19 tablas y 10 cuadros.

Madrid, 1983. Precios: España 2.100 ptas.; 30 \$ USA. 